\title{
Zur Kenntnis des Glutokyrins.
}

\author{
Von
}

M. Siegfried.

(Der Redaktion zugegangen am 19. August 1904.)

Die Analysen des Glutokyrinsulfates ${ }^{1}$ ) hatten für das Kyrin zu der Formel $\mathrm{C}_{21} \mathrm{H}_{39} \mathrm{~N}_{9} \mathrm{O}_{8}$ geführt. Diese Formel fand in Berücksichtigung der bei den Spaltungen des Kyrins gewonnenen Resultate ihre einfachste Erklärung in der Annahme, daß die Konstitution des Glutokyrins einer aus 1 Mol. Arginin, 1 Mol. Lysin, 1 Mol. Glutaminsäure und 2 Mol. Glykokoll unter Austritt von 4 Mol. Wasser aufgebauten Verbindung entspricht. Hierbei war die Bildung von Glykokoll bei der hydrolytischen Spaltung wahrscheinlich gemacht worden, aber nicht bewiesen. Dies wird in folgendem nachgeholt.

$40 \mathrm{~g}$ Sulfat $(\mathrm{C}=31,66 \%, \mathrm{H}=6,14 \%, \mathrm{~N}=15,80 \%$; berechnet $\mathrm{C}=31,86 \%, \mathrm{H}=5,61 \%, \mathrm{~N}=15,98 \%$ ) wurden mit $200 \mathrm{~g}$ Wasser und $100 \mathrm{~g}$ Schwefelsäure 6 Stunden gekocht. Die mit Wasser verdünnte Lösung wurde mit Phosphorwolframsäure ausgefällt, das Filtrat vom Phosphorwolframsäureniederschlag mit Baryt behandelt, der Überschuß des letzteren durch Ammonkarbonat entfernt. Der durch Eindampfen erhaltene Rückstand wurde in Wasser gelöst, die Glutaminsäure durch Silbernitrat und ammoniakalische Silberlösung gefällt. Das Filtrat wurde durch Schwefelammonium entsilbert, der eingedampfte und getrocknete Rückstand mit Alkohol zur Entfernung des Ammoniumnitrates ausgekocht. Der jetzt bleibende Rückstand wurde in wenig Wasser und etwas Ammoniak gelöst, mit Alkohol, bis die eben entstehende Trübung gerade

1) M. Siegfried, Ber. d. Königl. Sächs. Gesellsch. d. Wissensch., 1903, S. 63. 
noch verschwand, versetzt und in siedenden Alkohol eingetragen. Die nach dem Erkalten ausgeschiedenen Kristalle wurden aus verdünntem Alkohol unter allmählichem Zusatz von absolutem Alkohol umkristallisiert. Sie bildeten lange, kantige mikroskopische Prismen, wie auf gleiche Weise kristallisiertes Glykokoll. Diese schmolzen im Kapillarrohr bei $232^{\circ}$ (unkorr.), nachdem sie sich schon vorher gebräunt hatten.

Die Analyse bestätigte, daß Glykokoll vorlag:

I. 0,2051 g Substanz erforderten $27,15 \mathrm{ccm} \mathrm{n} / \mathbf{1 0}$

II. 0,1664 > gaben $0,1960 \mathrm{~g} \mathrm{CO}_{2}$ und $0,1066 \mathrm{~g} \mathrm{H}_{2} \mathrm{O}$.

\begin{tabular}{crr}
\multicolumn{2}{c}{ Gefunden: } & Berechnet für $\mathrm{C}_{2}$ \\
$\mathrm{G}$ & $32,18 \%$ & $31,96 \%$ \\
$\mathrm{H}$ & $6,97 \%$ & $6,71 \%$ \\
$\mathrm{~N}$ & $18,52 \%$ & $18,70 \%$
\end{tabular}

In diesem Falle und bei mehreren zu dem Zwecke ausgeführten kleineren Spaltungsversuchen wurde die Glutaminsäure über das Silbersalz bestimmt. In allen Fällen wurde viel weniger gefunden, als $1 \mathrm{Mol}$. der Säure auf $1 \mathrm{Mol}$. Kyrin entspricht. Man hat hier zunächst an 3 Möglichkeiten zu denken: Erstens kann die Spaltung in verschiedener Richtung erfolgen, ${ }^{1}$ ) zweitens können zum Teil sekundäre Produkte entstehen, wobei zunächst an die Pyrrolidonkarbonsäure zu denken ist, drittens können bei der Einwirkung der Schwefelsäure Verbindungen entstehen oder als Zwischenprodukte übrig bleiben, welche Glutaminsäure als Komplex enthalten.

Mit der Bearbeitung dieser Fragen ist Herr 0. Pilz im hiesigen Laboratorium beschäftigt.

1) Vgl. l. c., S. 84 . 